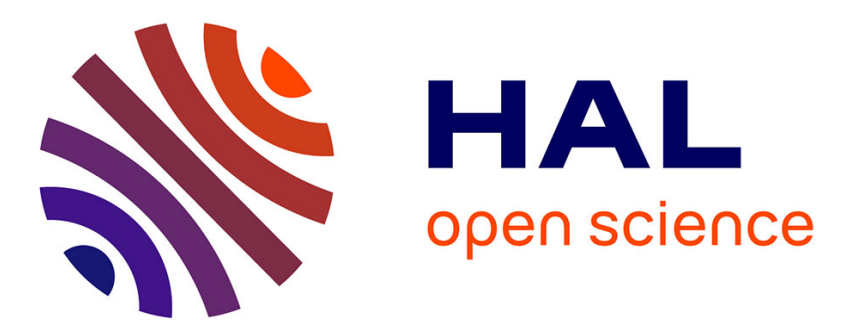

\title{
Relationships between radiographic parameters and spinopelvic muscles in adult spinal deformity patients
}

Emmanuelle Ferrero, Wafa Skalli, Virginie Lafage, Cédric Maillot, Robert Carlier, Antoine Feydy, Adrien Felter, Marc Khalife, Pierre Guigui

\section{- To cite this version:}

Emmanuelle Ferrero, Wafa Skalli, Virginie Lafage, Cédric Maillot, Robert Carlier, et al.. Relationships between radiographic parameters and spinopelvic muscles in adult spinal deformity patients. European Spine Journal, 2020, pp.1-12. 10.1007/s00586-019-06243-3 . hal-02523635

\section{HAL Id: hal-02523635 \\ https://hal.science/hal-02523635}

Submitted on 29 Mar 2020

HAL is a multi-disciplinary open access archive for the deposit and dissemination of scientific research documents, whether they are published or not. The documents may come from teaching and research institutions in France or abroad, or from public or private research centers.
L'archive ouverte pluridisciplinaire HAL, est destinée au dépôt et à la diffusion de documents scientifiques de niveau recherche, publiés ou non, émanant des établissements d'enseignement et de recherche français ou étrangers, des laboratoires publics ou privés. 


\title{
Relationships between radiographic parameters and spinopelvic muscles in adult spinal deformity patients
}

\author{
Emmanuelle Ferrero ${ }^{1,2} \cdot$ Wafa Skalli $^{2} \cdot$ Virginie Lafage $^{3} \cdot$ Cédric Maillot $^{2} \cdot$ Robert Carlier $^{4} \cdot$ Antoie Feydy $^{5}$. \\ Adrien Felter ${ }^{4} \cdot$ Marc Khalifé $^{1} \cdot$ Pierre Guigui ${ }^{1}$
}

\begin{abstract}
Introduction While the clinical impact of coronal and sagittal alignment in adult spinal deformity (ASD) patients (pts) is established, there is a paucity of data in terms of axial plane deformity and potential association between muscle degeneration and 3D deformity. The purpose of this study was to analyze spinopelvic muscles characteristics in association with the 3D deformity of ASD patients.

Methods This is a prospective cohort study; primary lumbar scoliosis patients $\left(\mathrm{Cobb}>20^{\circ}\right)$ were enrolled and sustained a low-dose X-rays with 3D spinal reconstructions and a fat/water separation MRI (from C7 to the knee). Volumetric 3D reconstructions and fat infiltration (FI) of 6 muscles groups were performed. Relationships between muscular data, radiographic parameters and health-related quality of life were investigated. Patients were stratified and compared based on the SRS classification, the odontoid-hip axis (ODHA) angle $\left(>\right.$ or $\left.<6.1^{\circ}\right)$ and occurrence of rotatory subluxation.

Results and discussion Twenty-eight patients were enrolled with a mean age of $60 \pm 16 y$ and mean body mass index of $26 \pm 4 \mathrm{~kg} / \mathrm{m}^{2}$ without differences between groups. There were a moderate sagittal malalignment and a Cobb angle of $45 \pm 11^{\circ}$ (table). Muscular volume was smaller in patients with more severe deformity $(p>0.05)$. Pts with ODHA $>6.1^{\circ}$ or pelvic incidence minus lumbar lordosis $>10^{\circ}$ had significantly higher FI for the 6 muscular groups, patients with pelvic tilt $>20^{\circ}$ had significantly higher FI for erector spinae, hip flexors and extensors $(p<0.05)$. SF36-PCS significantly correlated with the muscular volume; SRS and Oswestry disability index correlated with the erectors spinae volume $(p<0.05)$.

Conclusion This study analyzed for the first time the relationship between 3D radiographic parameters and muscular characteristics in ASD. Sagittal malalignment is associated with increased FI and decreased muscle volumes with poor outcomes.
\end{abstract}

Keywords Adult spinal deformity $\cdot$ Muscle degeneration $\cdot 3 \mathrm{D}$ analysis $\cdot$ Scoliosis $\cdot$ Fat infiltration 


\section{Introduction}

With aging of the population worldwide, prevalence of adult scoliosis is increasing and associated corrective surgery is more and more frequent [1]. While the disability of adult spinal deformity (ASD) has been clearly established in the literature [2,3]. Its physiopathology remains unclear; multiple degenerative processes have been evoked such as bone, muscles, disks and central nervous system degeneration. Therefore, ASD analysis is complex.

When sagittal alignment occurs, several compensatory mechanisms may be recruited in an effort to maintain an erected posture, such as pelvic retroversion with hip hyperextension, knee flexion, or change in thoracic alignment (flattening), after activation of different muscle groups [4-6]. Thereby, a better understanding of the role of muscles and their degeneration in the evolution of adult scoliosis may lead to a better understanding of the pathology and therefore better treatments. To date, very few studies have investigated the role of the muscular system in the regulation of the sagittal alignment. Research on subjects without spinal deformities demonstrated an increase in fat infiltration of nearly $15 \%$ with aging [7]. Similarly, some authors have observed a decrease in volume and an increase in fat infiltration of spinal erectors in patients with loss of lumbar lordosis [8]. Others have found an association between this increase in fat infiltration and the functional discomfort associated with low back pain [9]. Nevertheless, most of these studies analyzed surface (cross-sectional area, CSA) and did include a reliable method to investigate muscular volume.

The use of new 3D reconstruction methods with MRI makes it possible to better quantify and characterize muscles, thus to better understand their impact on spinal deformity and its evolution [10-12]. Moal et al. were the first to use this specific MRI in spinal pathology; they described the muscles characteristics of 19 adult patients with spinal deformity [11]. Amabile et al., more recently, from a cohort of young, non-deformed subjects, reported muscle volume values from T12 to the femoral condyles, thus constituting the first database of asymptomatic subjects [10]. However, none of these studies analyzed the relationships between radiographic and muscular parameters, and to our knowledge, no work exists on the relationship between the existence of a rotatory subluxation and soft tissue degeneration (particularly muscles).

Thus, to better understand muscles degeneration phenomena, such as fat infiltration and loss of volume, associated with the spinal deformity, the objective of this work was to describe the characteristics of the spinal and pelvic muscles in a population of patients with adult lumbar scoliosis and analyze their relationship with 3D radiographic parameters, including rotatory subluxation. Our hypothesis was that coronal, sagittal and axial deformity was responsible for muscles degeneration.

\section{Methods}

\section{Study}

This prospective cohort study was compiled between 2016 and 2018, after local ethic committee approval. Patients over 40 years of age, with a primary degenerative lumbar scoliosis and a Cobb angle greater than $20^{\circ}$, were included. Exclusion criteria included patients with history of spinal surgery and other causes of scoliosis (ie, neurological, congenital, traumatic, neoplastic).

\section{Demographic and clinical data}

For each patient, the following demographic data were recorded: age, sex, body mass index (BMI). Different healthrelated quality of life scores (HRQOL) were collected: the Oswestry disability index (ODI), the Scoliosis Research Society 30 (SRS30) and the Short Form 12 mental and physical component (SF12-MCS and SF12-PCS), visual analog scale for lumbar pain (VAS-L) [13-17].

\section{Radiographic analysis}

All patients sustained a low-dose biplanar full-spine X-rays, in standing position, with the EOS system (EOS imaging, Paris, France). X-rays were performed according to a standardized free standing protocol to avoid superimposition of the arm on the spine [18]. All images included at least the skull to the femoral heads. From the biplanar radiographic acquisitions, the $3 \mathrm{D}$ reconstructions of the spine were performed with an adapted methods of sterEOS software (EOS imaging, Paris, France), from the identification of specific anatomical points [19]. Thus, the vertebrae $\mathrm{C} 2$ to $\mathrm{S} 1$, the pelvis with the 2 femoral heads were reconstructed.

In the coronal plane, the Cobb angle of the main lumbar curve was measured. Coronal imbalance was defined as coronal $\mathrm{C} 7$ coronal tilt greater than $3^{\circ}$. In the sagittal plane, spinal parameters analyzed were L1S1 lordosis, T1T12 kyphosis, and pelvic parameters with pelvic incidence (PI), pelvic tilt (PT) and sacral slope (SS). Overall sagittal alignment was measured with $\mathrm{T} 1$ spinopelvic inclination angle (T1SPi) [20] and the ODHA angle, angle between the vertical reference line the line joining the summit of the odontoid (OD) and the center of the hip axis (HA) [21-23] (Fig. 1). Sagittal malalignment was also described using the 3 parameters of the SRS-Schwab classification: SVA greater than $40 \mathrm{~mm}$, the difference between pelvic incidence and lumbar 


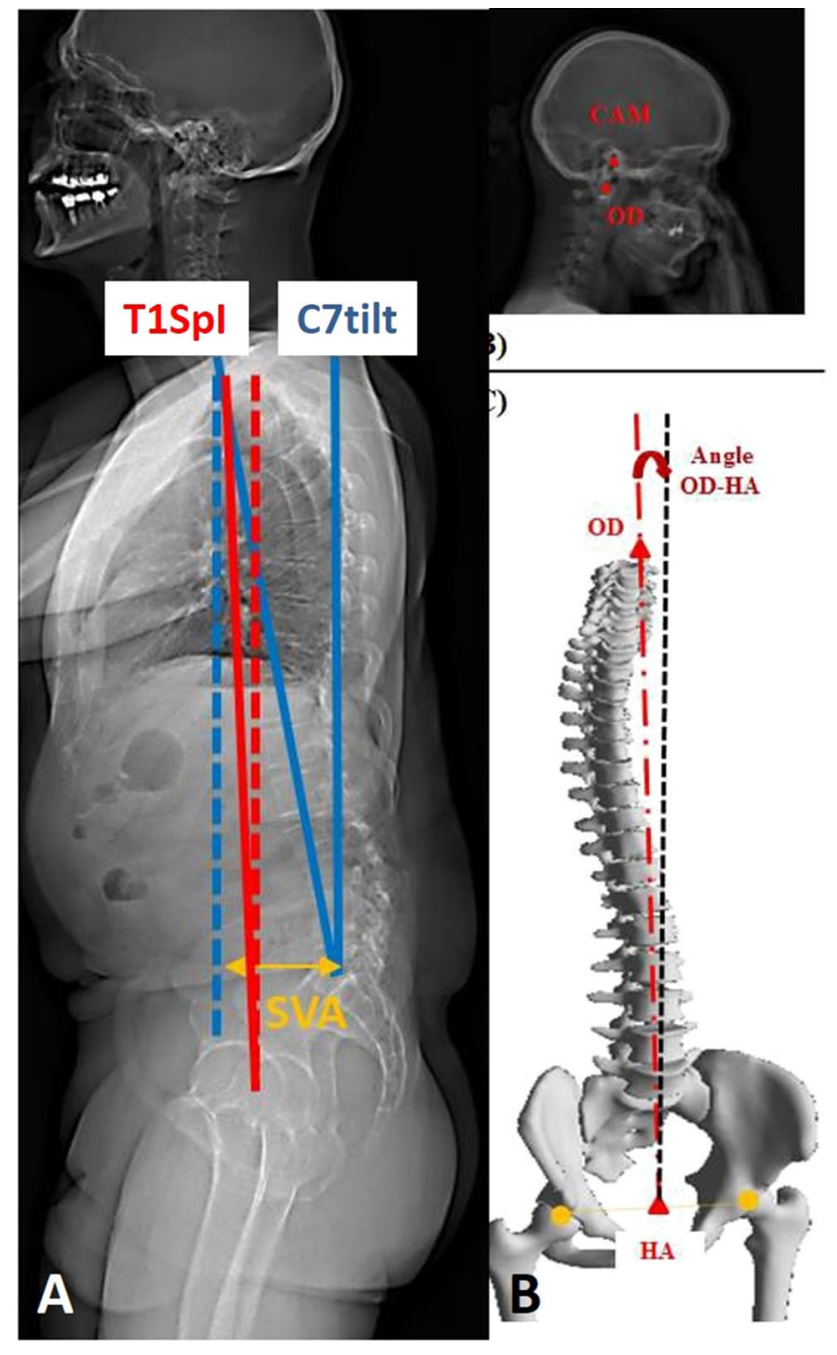

Fig. 1 Global sagittal alignment parameters: T1 spinopelvic inclination angle (T1SPi), C7 tilt, sagittal vertical axis (SVA), odontoid (OD) and the center of the hip axis (HA) angle (ODHA)

lordosis (PI-LL) greater than $10^{\circ}$, and pelvic tilt greater than $20^{\circ}$ [24]. In the axial plane, axial intervertebral rotation (AIR) was defined as the rotation of the superior vertebra with respect to the underlying vertebra. Therefore, rotatory subluxation was defined by an axial intervertebral rotation greater than $5^{\circ}$ and by a lateral listhesis of more than $3 \mathrm{~mm}$ on the frontal radiograph. Patients were separated into two groups: those with rotary subluxation (RS) and those without (non-RS).

\section{MRI analysis}

All patients had MRI from C7 vertebra to the femoral condyles. The axial slices were consecutive, parallel and contiguous with a constant thickness of $5 \mathrm{~mm}$. The fat/ water separation MRI protocol used was the same as the one described in a previous study (Dixon method) [25].The

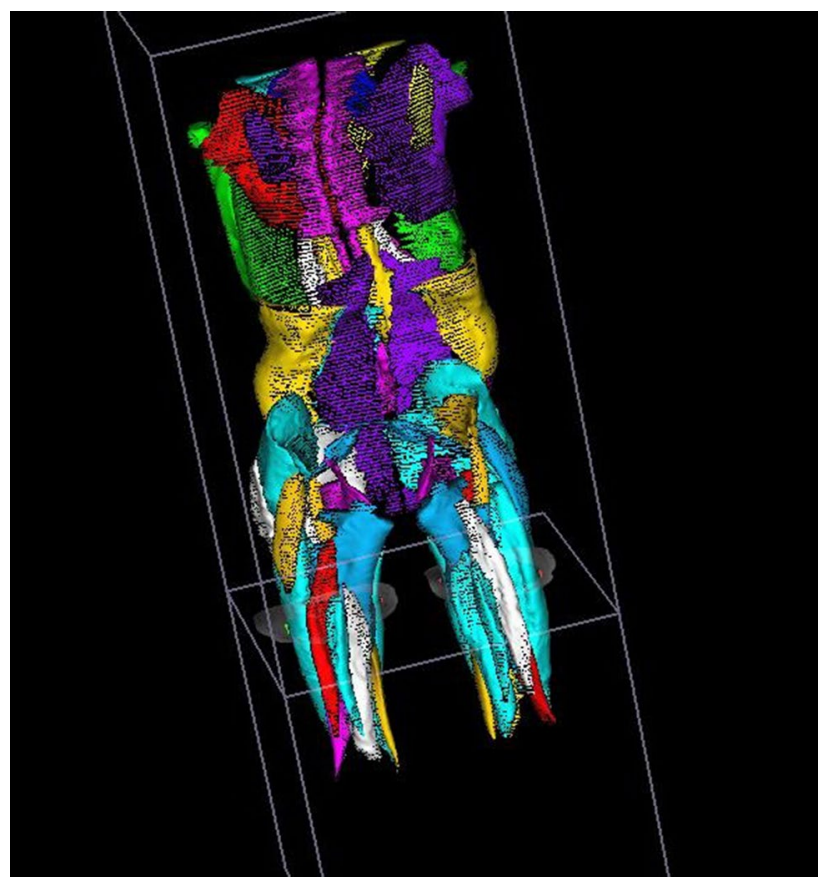

Fig. 2 Volumetric 3D muscular reconstruction of an ASD patient

MRI machine was set with the following parameters: TR/ $\mathrm{TE}=427 / 11.3 \mathrm{~ms}$, acquisition matrix $=416 * 416$ pixels, phase oversampling $=100 \%$, in plane resolution $=0.82 \mathrm{~mm}^{2}$, 8 stages, 40 slices by stage, slice thickness $=5 \mathrm{~mm}$, slice gap $=0 \mathrm{~mm}$, parallel imaging acceleration factor $(\mathrm{iPat})=2$, bandwidth $=391 \mathrm{~Hz} /$ pixel, echo spacing $=11.3 \mathrm{~ms}$, acquisition time per stage $=7 \mathrm{~min}$, total acquisition time $=50 \mathrm{~min}$ [26, 27]. A first set of images where the intensity of each voxel was correlated with the amount of water (Water image) and a second set of images where the intensity of each voxel was correlated with the amount of fat (Fat image) were automatically generated. These two sequences had exactly the same slices' positions and orientations.

Using the DPSO (deformation of parametric specific object) method with dedicated software (Muscl'X, ENSAM, Paris, France), volumetric 3D reconstructions and fat infiltration (FI) of right and left muscles were performed (with information from all MRI slices) [28] (Fig. 2). The fat infiltration (FI) of 30 muscles was also evaluated by a calibration between a pure fat zone in the subcutaneous area $(100 \% \mathrm{FI})$ and a pure muscular zone in the psoas $(0 \% \mathrm{FI})$. Six muscle groups were defined: the posterior muscles of the thoracic belt (trapezius, rhomboid, latissimus dorsi), the erectors spinae (spinalis, longissimus and iliocostalis) and the flexors of the spine (abdominal, psoas, iliacs, quadratus lumborum, external and internal obliquus and transversalis), the hip extensors (biceps femoris, semi-tendinous, semi-membranous) and hip flexors (quadriceps and sartorius) and the pectorals (small and large). The erector spinae were analyzed in 
total from $\mathrm{T} 1$ to sacrum. The volume ratio of each muscle relative to the total muscle volume was also calculated.

\section{Statistical analysis}

Statistical analysis was performed with Stata software version 15.0 (Statacorp, College Station, Texas). The normal distribution of the variables was verified by Shapiro Wilk's test. A descriptive analysis of the demographic, clinical, radiographic and MRI (muscle volume and fat infiltration) was performed. Muscle data from the MRI were compared between the sides of the concavity and convexity. Then, the relationships between muscle characteristics, radiographic and clinical parameters were analyzed. Different patients groups were defined according SRS-Schwab classification criteria (SVA greater than $40 \mathrm{~mm}$, PI-LL greater than $10^{\circ}$, and pelvic tilt greater than $20^{\circ}$ ) and abnormally high ODHA value (greater than $6.1^{\circ}$, based on analysis of asymptomatic subjects) [10, 21, 24]. Muscles characteristics (volume and FI) of patients were compared between these groups. Finally, the radiographic and muscular data of the two groups of patients without and with RS were compared. A value of $p<0.05$ was considered significant.

\section{Results}

\section{Patients}

Twenty-eight patients were enrolled, with $71 \%$ of women $(n=20)$. The mean age was $60 \pm 16$ years ( $40-81$ years), and the average BMI was $26 \pm 4 \mathrm{~kg} / \mathrm{m}^{2}$.

Nineteen patients completed clinical scores. The mean SRS score was $2.8 \pm 0.9$ (2.2-4.4), the ODI score was $37.2 \pm 21$ with a large range of values from 4 to 60 . Regarding quality of life, the mean value of the mental component of the SF36 was the highest (SF36 MCS $=45.3 \pm 11.5$ (35-58), SF36 PCS $=33.5 \pm 10.5$ (22-52). The mean value of the VAS-L was $6.7 \pm 2.7$ (2-9.3), and that of the VAS-R was $4.1 \pm 3.9(0-8.9)$.

\section{Radiographic analysis}

The mean lumbar Cobb angle was $45 \pm 11^{\circ}\left(24^{\circ}-64^{\circ}\right)$. Twenty-one patients had a coronal malalignment (in 13 cases on the left). The average coronal tilt was $2.6 \pm 2.2^{\circ}$ $\left(0^{\circ}-8.9^{\circ}\right)$. The axial rotation of the apical vertebra was $28.6 \pm 9.9^{\circ}\left(10^{\circ}-46^{\circ}\right)$.

The radiographic parameters are reported Table 1. Fourteen patients had SVA $>40 \mathrm{~mm}, 10$ had PT $>20^{\circ}, 14$ had PI-LL $>10^{\circ}$, and 8 had ODHA $>6.1^{\circ}$.

The total muscular volume was $10 \pm 3 \mathrm{dm}^{3}$. A great variability of values was observed between the different muscles
Table 1 Sagittal radiographic parameters of 28 adults with lumbar scoliosis

\begin{tabular}{lllll}
\hline & Mean & SD & Min & Max \\
\hline Pelvic incidence $\left(^{\circ}\right)$ & 55 & 11 & 31 & 80 \\
Pelvic tilt $\left(^{\circ}\right)$ & 21 & 8 & 10 & 38 \\
L1S1 $\left(^{\circ}\right)$ & 43 & 21 & 10 & 89 \\
PI-LL $\left(^{\circ}\right)$ & 11 & 16 & -17 & 37 \\
T1T12 $\left(^{\circ}\right)$ & 38 & 15 & 2 & 75 \\
C3C7 $\left(^{\circ}\right)$ & 23 & 16 & -9 & 48 \\
SVA $(m m)$ & 51 & 49 & -71 & 146 \\
ODHA $\left(^{\circ}\right)$ & 5.9 & 5.1 & 1.26 & 18.7 \\
\hline
\end{tabular}

and between patients, as evidenced by the large range of volume and fat infiltration (FI) values (Fig. 3) (Table 2). For none of the thirty muscles, volumes were significantly different between the right and left sides, concavity and convexity. Increased infiltration for the erector spinae, abdominal, oblique and dorsal erectors was observed with regard to other muscles groups.

\section{Comparison of patients' muscular volume according to the importance of sagittal deformity}

The comparison of patients' total muscular volume according to the severity of sagittal deformity (Table 3 ) showed no significant difference either in total volume nor volume of any of the muscle groups (PT $>$ or $<20^{\circ}: 8.9 \pm 3.5 \mathrm{dm}^{3}$ vs. $10.5 \pm 2.7 \mathrm{dm}^{3}, p=0.20$; SVA $>$ or $>40 \mathrm{~mm}: 9.9 \pm 3.1 \mathrm{dm}^{3}$ vs. $10.4 \pm 3.0 \mathrm{dm}^{3}, p=0.49$; PI-LL $>$ or $<10^{\circ}: 9.7 \pm 1.7 \mathrm{dm}^{3}$ vs. $10.2 \pm 3.9 \mathrm{dm}^{3}, p=0.72$; ODHA $>$ or $<6.1^{\circ}: 9.9 \pm 2.2$ $\mathrm{dm}^{3}$ vs. $10.2 \pm 2.2 \mathrm{dm}^{3}, p=0.83$ ). The muscles volumes of patients with an ODHA $>6.1^{\circ}$ tend to be lower than the volumes of the other patients, except for the spinal flexors.

\section{Comparison of patients' muscular fat infiltration according to the importance of sagittal deformity}

In contrast, comparison of patients' muscular fat infiltration according to the severity of sagittal deformity demonstrated significant differences between groups (Table 4).

FI was greater for all muscle groups in patients with $\mathrm{PT}>20^{\circ}$ than those with $\mathrm{PT}<20^{\circ}$ and significantly for spinal erectors, hip flexors and extensors. The detailed analysis of the gluteus medius revealed that if the volume was not different between the 2 groups $\left(0.54 \pm 0.06 \mathrm{dm}^{3}\right.$ vs. $0.52 \pm 0.07$ $\mathrm{dm}^{3}, p=0.66$ ), fat infiltration was greater in the group with greater retroversion $(30 \% \pm 12$ vs. $19 \% \pm 9, p=0.008)$.

FI was greater for all muscle groups in patients with SVA $>40 \mathrm{~mm}$ and significantly for upper thoracic muscles, erectors and flexors of the spine. 


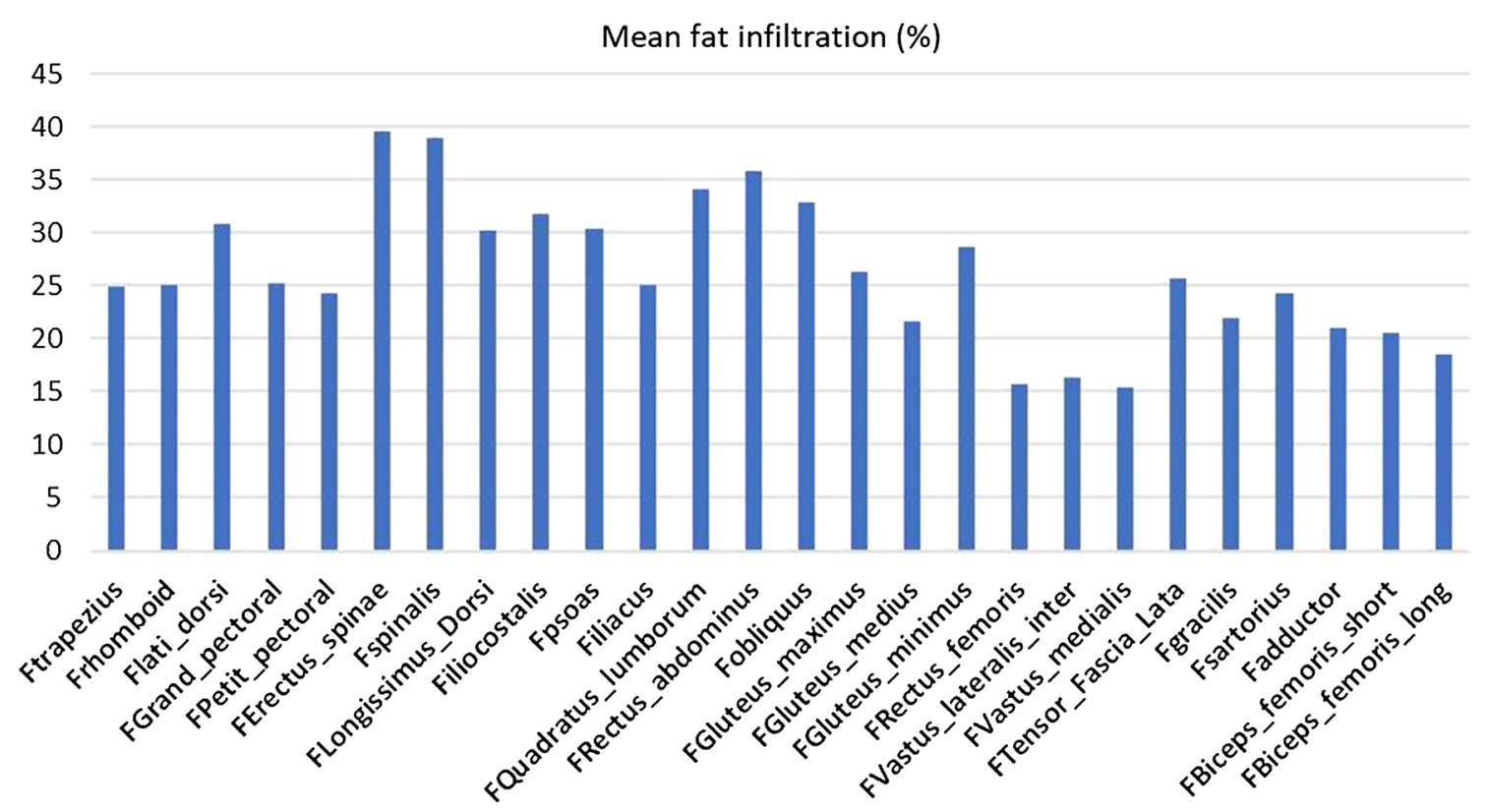

Fig. 3 Fat infiltration of the main spinopelvic muscles

Table 2 Fat infiltration (FI) and volume (V) of the muscles groups in the cohort $(n=28)$

\begin{tabular}{lllll}
\hline & Mean & SD & Min & Max \\
\hline FI thoracic belt (\%) & 27 & 15 & 3 & 54 \\
FI pectoral (\%) & 25 & 13 & 4 & 63 \\
FI erector spinae (\%) & 34 & 13 & 7 & 61 \\
FI flexor spinae (\%) & 32 & 12 & 11 & 52 \\
FI hip extensor (\%) & 19 & 11 & 5 & 61 \\
FI hip flexor (\%) & 18 & 12 & 6 & 66 \\
V thoracic belt $\left(\mathrm{dm}^{3}\right)$ & 0.53 & 0.23 & 0.21 & 1.19 \\
V pectoral $\left(\mathrm{dm}^{3}\right)$ & 0.41 & 0.17 & 0.20 & 1.03 \\
V erector spinae $\left(\mathrm{dm}^{3}\right)$ & 0.92 & 0.18 & 0.57 & 1.36 \\
V flexor spinae $\left(\mathrm{dm}^{3}\right)$ & 1.28 & 0.29 & 0.81 & 2.06 \\
V hip extensor $\left(\mathrm{dm}^{3}\right)$ & 0.94 & 0.26 & 0.41 & 1.54 \\
V hip flexor $\left(\mathrm{dm}^{3}\right)$ & 2.35 & 0.74 & 0.11 & 4.11 \\
\hline
\end{tabular}

Similarly, FI was significantly greater for all muscle groups in patients with loss of lumbar lordosis of more than $10^{\circ}$, except for the abdominals. Detailed analysis of the obliquus and psoas revealed that if the volume was not different between the 2 groups of patients (respectively, $0.41 \pm 0.08 \mathrm{dm}^{3}$ vs. $0.44 \pm 0.07 \mathrm{dm}^{3}, \mathrm{p}=0.71$ and $0.44 \pm 0.03 \mathrm{dm}^{3}$ vs. $\left.0.44 \pm 0.04 \mathrm{dm}^{3}, p=0.58\right)$, the fat infiltration was greater in the group with a greater loss of lordosis (respectively, $37 \% \pm 11$ vs. $29 \% \pm 10, p=0.04$ and $36 \% \pm 11$ vs. $25 \% \pm 12, p=0.03$ ). Fat infiltration of the gluteus medius was also greater in this group $(26 \% \pm 8$ vs. $17 \% \pm 9, p=0.01$ ).
FI tended to be greater for all muscle groups in patients with ODHA $>6.1^{\circ}(p>0.05)$, except for abdominals (Fig. 4).

\section{Comparison of patients with and without rotatory subluxation (RS) (Table 5 )}

Seventeen patients $(61 \%)$ presented with RS, most often at L3L4 level (76\% of cases, $n=13)$. Demographics were not significantly different between patients with and without RS. The radiographic parameters are reported in Table 1, without difference between groups. The average Cobb angle was $45 \pm 11^{\circ}$. Nevertheless, in the sagittal plane, patients with RS had a tendency to a greater loss of lordosis $\left(15 \pm 15^{\circ} \mathrm{vs}\right.$. $\left.7 \pm 15^{\circ}, p>0.05\right)$ and to a larger anterior tilt $\left(0.6 \pm 7^{\circ}\right.$ vs. $\left.-1.4 \pm 4^{\circ}, p>0.05\right)$. Mean intervertebral axial rotation at the rotatory subluxation stage was $17.0 \pm 5^{\circ}$.

The average total volume of the muscles was $10 \pm 2 \mathrm{dm}^{3}$. There was a nonsignificant difference of $1.4 \mathrm{dm}^{3}$ in total volume between the 2 groups of patients. The spinal erectors and flexors, and the hip flexors were smaller in the RS group, but without significant difference, while the volume of the abdominus and hip extensors was similar between the groups.

The particular study of the volume of spinalis, longissimus, iliocostalis, psoas and gluteus medius did not find any significant difference between the 2 groups of patients, although the volumes are always lower in the RS group (on average of $0.1 \mathrm{dm}^{3}$ ).

Fat infiltration was more important for patients with RS (particularly spinal erectors, hip extensors and abdominus) between $20-42 \%$ versus $17-35 \%$ fat infiltration for patients 


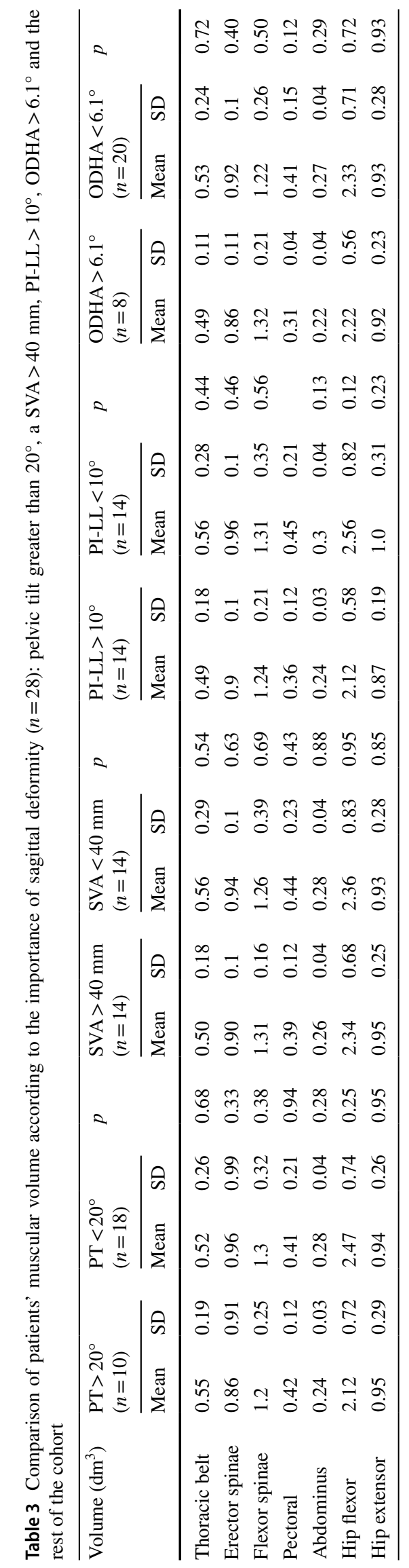

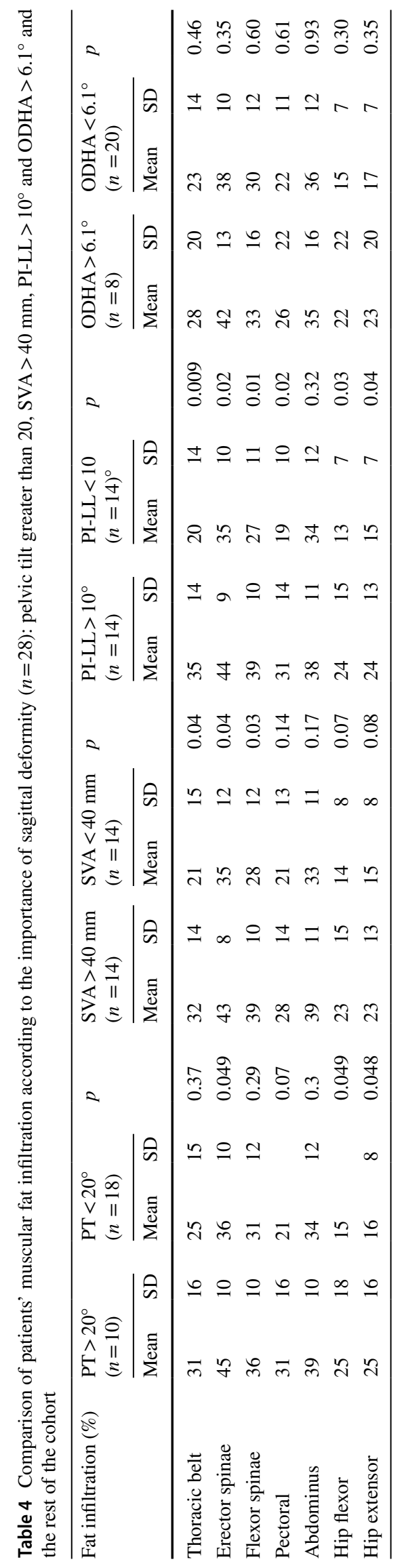




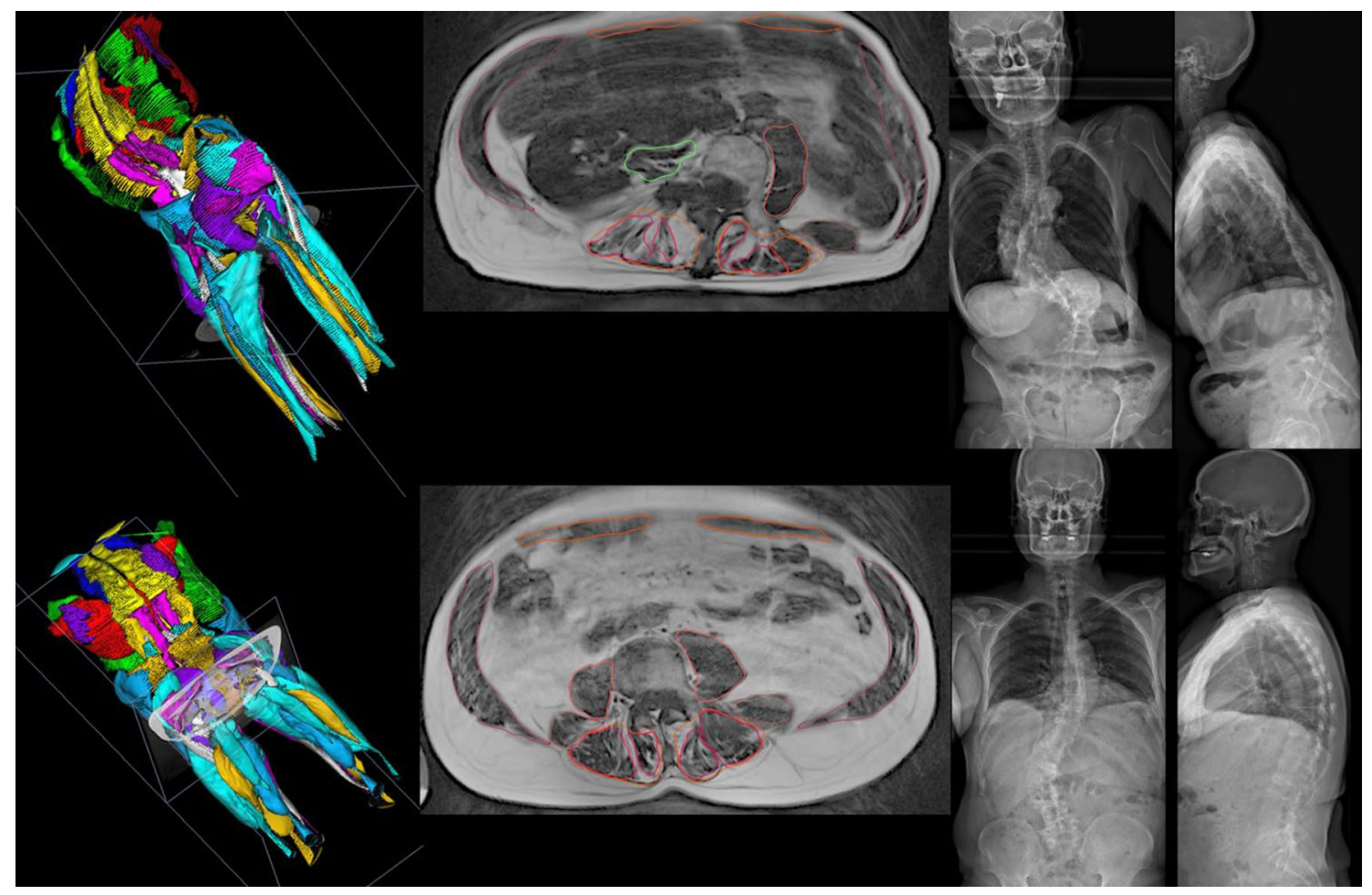

Fig. 4 Muscular reconstructions of a patient with ODHA $>6.1^{\circ}$ (top) and a patient with ODHA $<6.1^{\circ}$ (bottom). Higher FI and less muscles volume is observed on patient with ODHA $>6.1^{\circ}$

Table 5 Comparison of muscle volumes and fat infiltration between patients with and without RS

\begin{tabular}{|c|c|c|c|c|c|c|c|c|c|c|}
\hline & \multicolumn{4}{|c|}{ Volume $\left(\mathrm{dm}^{3}\right)$} & \multirow{3}{*}{$p$} & \multicolumn{5}{|c|}{ Fat infiltration (\%) } \\
\hline & \multicolumn{2}{|c|}{$\begin{array}{l}\text { Without RS } \\
(n=11)\end{array}$} & \multicolumn{2}{|c|}{$\mathrm{RS}(n=17)$} & & \multicolumn{2}{|c|}{$\begin{array}{l}\text { Without RS } \\
(n=11)\end{array}$} & \multicolumn{2}{|c|}{$\mathrm{RS}(n=17)$} & \multirow[t]{2}{*}{$p$} \\
\hline & Mean & SD & Mean & $\mathrm{SD}$ & & Mean & SD & Mean & SD & \\
\hline Thoracic belt & 0.57 & 0.27 & 0.51 & 0.23 & 0.57 & 26 & 17 & & 15 & 0.70 \\
\hline Erector spinae & 0.97 & 0.90 & 0.90 & 0.97 & 0.35 & 22 & 11 & 42 & 13 & 0.09 \\
\hline Flexor spinae & 1.31 & 0.36 & 1.27 & 0.26 & 0.76 & 31 & 15 & 34 & 11 & 0.59 \\
\hline Pectoral & 0.45 & 0.24 & 0.39 & 0.14 & 0.39 & 22 & 13 & 26 & 14 & 0.50 \\
\hline Abdominus & 0.7 & 0.2 & 0.7 & 0.2 & 0.76 & 29 & 10 & 35 & 9 & 0.17 \\
\hline Hip flexor & 2.48 & 0.83 & 2.28 & 0.70 & 0.50 & 17 & 9 & 20 & 14 & 0.15 \\
\hline Hip extensor & 0.94 & 0.28 & 0.94 & 0.26 & 0.99 & 18 & 9 & 23 & 13 & 0.61 \\
\hline
\end{tabular}

Significant correlations existed between radiographic and muscle parameters. Axial intervertebral rotation correlated with the fat infiltration of several muscle groups, specifically psoas, spinal erectors, latissimus dorsi, abdominus and obliquus $(0.65<R<0.89, p<0.05)$. SVA was moderately correlated with fat infiltration of the spinal erector $(0.46<R<0.51, p<0.05)$. The PI-LL mismatch was moderately correlated with increased fat infiltration of all muscle groups $(0.456<R<0.551, p<0.05)$. The detailed muscle analysis revealed significant correlations between pelvic tilt and abdominus volume $(R=-0.426, p<0.05)$.
Age was inversely correlated with hip flexor and psoas volumes $(R=-0.553, p<0.05)$. BMI correlated with volumes of spinal erectors, spinal flexors, psoas and obliquus $(0.413<R<0.687, p<0.05)$. 


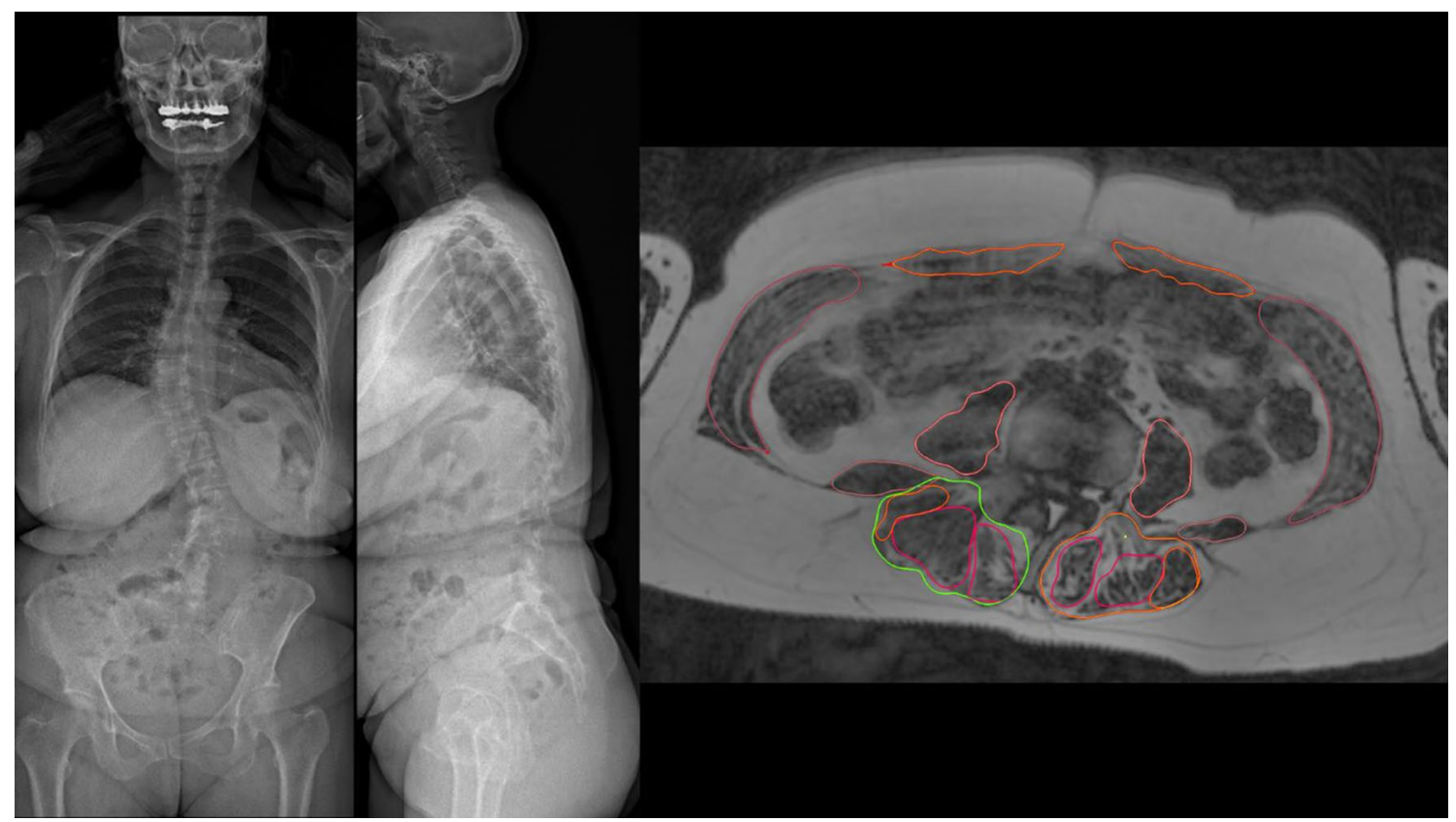

Fig. 5. Sixty-one-year-old patient with L3L4 rotatory subluxation, with significant fat infiltration of muscles, particularly spinal erectors and abdominals

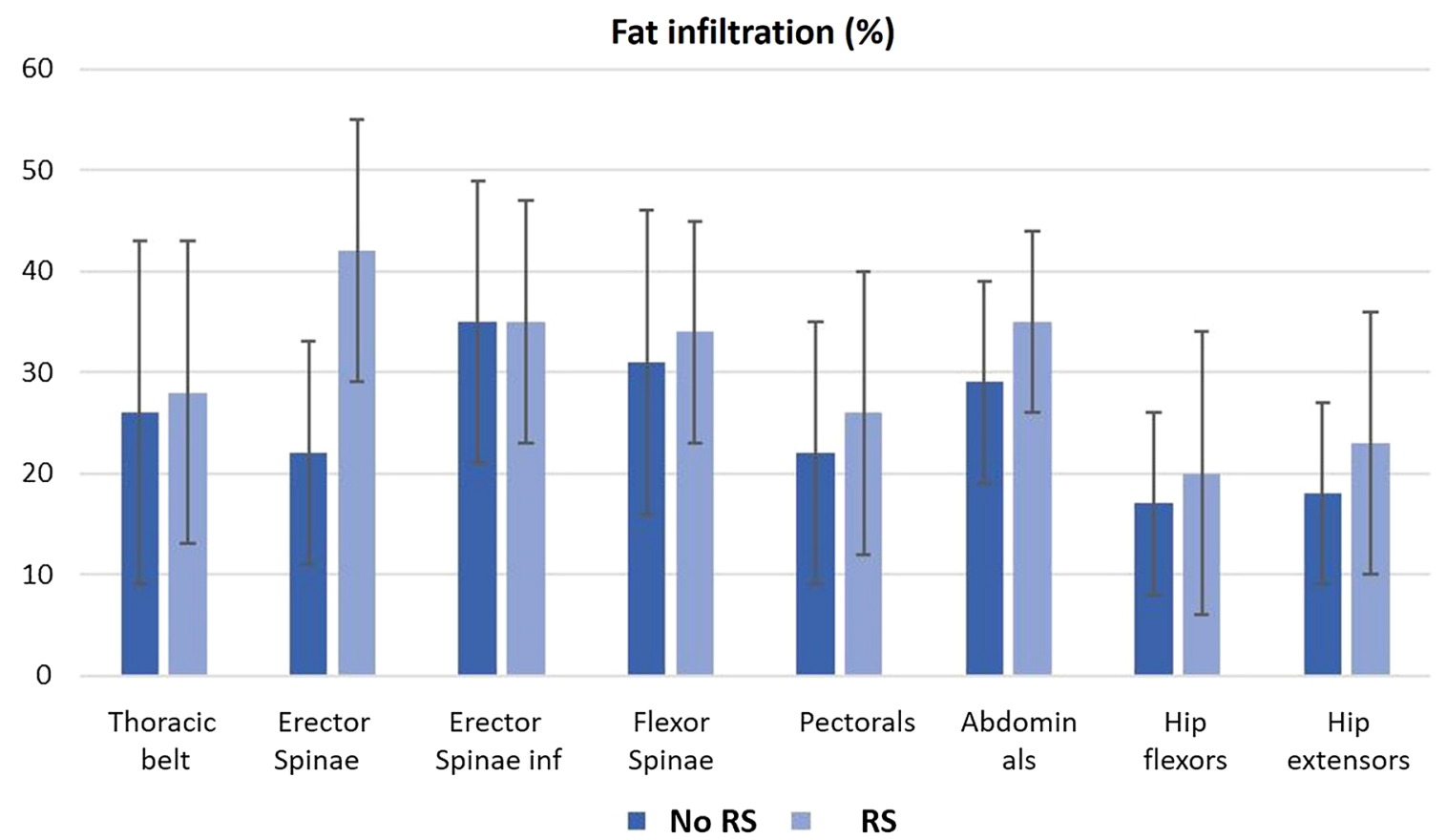

Fig. 6 Histogram of the fat infiltration between patients with and without rotatory subluxation

No correlation was found between muscle parameters and cervical lordosis or thoracic kyphosis.

Correlations were also observed between the clinical scores available for 19 patients and the muscle parameters. The physical component of the SF12 quality of life score correlated well with the volume of spinal erector $(R=0.662$, $p<0.05)$, psoas $(R=0.767, p<0.05)$, gluteal means $(R=0.729, p<0.05)$. SRS 30 and ODI correlated with spinal erector volume (respectively, $R=0.750$ and $R=0.640$, $p<0.05)$. No correlation with fat infiltration was observed. 
Table 6 Analysis of correlations between radiographic, demographic and muscular parameters $(n=28)$ (AIR RS: axial intervertebral rotation at the rotatory subluxation level)

\begin{tabular}{|c|c|c|c|c|c|c|c|}
\hline & Age & BMI & PT & L1S1 & PI-LL & SVA & AIR RS \\
\hline \multicolumn{8}{|l|}{$V$ thoracic belt $\left(\mathrm{dm}^{3}\right)$} \\
\hline \multicolumn{8}{|l|}{$V$ pectoral $\left(\mathrm{dm}^{3}\right)$} \\
\hline$V$ erector spinae $\left(\mathrm{dm}^{3}\right)$ & & 0.587 & & & & & \\
\hline V flexor spinae $\left(\mathrm{dm}^{3}\right)$ & & 0.618 & & & & & \\
\hline \multicolumn{8}{|l|}{ V hip extensor $\left(\mathrm{dm}^{3}\right)$} \\
\hline V hip flexor $\left(\mathrm{dm}^{3}\right)$ & -0.538 & & -0.396 & & -0.43 & & \\
\hline FI thoracic belt (\%) & & & & -0.503 & 0.456 & & \\
\hline FI pectoral (\%) & & & & -0.465 & 0.463 & & \\
\hline FI erector spinae (\%) & & & 0.423 & -0.544 & 0.484 & 0.465 & 0.755 \\
\hline FI flexor spinae (\%) & & & 0.4 & -0.561 & 0.511 & 0.409 & 0.645 \\
\hline FI hip extensor (\%) & & & & -0.492 & 0.541 & 0.415 & \\
\hline FI hip flexor (\%) & & & & -0.502 & 0.551 & & 0.533 \\
\hline
\end{tabular}

\section{Discussion}

In this study, in addition to analyzing the 3D radiographic parameters of a cohort of patients with adult lumbar scoliosis, we provided information on the characteristics of major spinal and pelvic muscle groups. This study also established relationships between radiographic data of the deformity and muscle data (particularly Cobb angle, SVA and axial rotation); the importance of deformity was associated with a significant increase in fat infiltration and a tendency to decrease certain muscle volume.

A large intermuscular and interindividual variability was observed for muscle volumes and fat infiltration (Fig. 3). The muscle group most affected by FI was the spinal erector group (34\%), followed by the spinal flexors (32\%). The least affected muscles were hip flexors and extensors (19\% and 18\%). Moal et al., in a study of 19 women with spinal deformity, found similar results with $31.9 \%$ fat infiltration of the same group [25]. However, they described a more important fat infiltration of the hip extensors.

In our study, the analysis of the relationships between muscles and deformity demonstrated that sagittal deformity was associated with significantly greater fat infiltration. This concerned particularly the flexors and extensors of the spine, in the case of pelvic retroversion of more than $20^{\circ}$, of SVA of more than $40 \mathrm{~mm}$, of PI-LL of more than $10^{\circ}$. Pelvic retroversion was also associated with increased fat infiltration of the gluteus medius. In addition, in the case of lack of lumbar lordosis, all muscle groups had increased fat infiltration. All of these degenerative phenomena may be associated with difficulty in maintaining an erect posture. Relationships have also been observed between intervertebral axial rotation and muscle degeneration. One of our hypotheses was that muscle degeneration could be more important in the concavity of the curvature. However, no difference could be detected between the muscles of concavity and convexity, whereas
Shafaq et al. observed a fat degeneration of the psoas more important in the concavity of the curvature [29].

While correlations were observed between the volume of the hip flexor and age, these correlations were not found with the extensor or flexor muscles of the spine, showing that the degeneration of these muscles was not only related to the physiological aging changes but that there is a close association with the deformity. Analysis of correlations with radiographic and muscular parameters confirmed the relationship between deformity and involvement of the main muscles responsible for maintaining spinopelvic alignment. Indeed, a defect in the sagittal alignment was associated with an increase in the fat infiltration of the spinal erector, thus making it possible to explain the failure to maintain the extension of the spine. In addition, there were even more important correlations between axial intervertebral rotation at the level of rotatory subluxation and fat infiltration of spinal erectors and flexors, as well as with hip flexors. These results suggested an overall muscle degeneration in these patients with degenerative scoliosis. Yagi and Shafaq obtained similar conclusions with a more important decrease of psoas and multifidus volume in patients with degenerative scoliosis than in those with a single lumbar spinal stenosis. They also observed fat infiltration of spinal erectors proportional to the Cobb angle, but these studies were performed from cross-sectional area analysis on a single lumbar level [29, 30].

In adult degenerative scoliosis, there are an evolution of the deformity with the appearance of rotary subluxation and an aggravation of the lateral or anterior tilt, which can lead the patient in a situation of great imbalance. The factors responsible for this aggravation are not clearly defined. Nevertheless, in this study, a trend of decreased volume of erectors and flexors of the spine, but also of the extensors and flexors of hip in patients with RS, was observed. More than the loss of volume, it is the fat infiltration of these 4 muscle groups that was greater in patients with RS (23-42\%) 
than those without RS (13-29\%). It is interesting to note that the fat infiltration values of patients without RS were close to the values found by Moal et al. in his study on ASD women [25].

Given the muscular degeneration in patients with spinal deformity but also existing relationships between muscle characteristics and radiographic parameters of the deformity, it might be interesting to perform a preoperative exploration of these patients and offer a pre-habilitation program. These findings may help to choose the length of fusion by not stopping in the thoraco-lumbar zone in the case of advanced muscular degeneration in order to avoid the occurrence of junctional kyphosis. Hyun et al., for example, in its series of 44 operated adult scoliosis found that a fat infiltration of spinal erectors of more than $60 \%$ was a risk factor for postoperative junctional kyphosis [31].

\section{Limitations}

This study had some limitations, including the small size of the cohort, which may explain the lack of significant difference on some results. One of the reasons of the small cohort is the MRI method which is very specific and difficult to perform; the other reason is that MRI reconstructions are very time-consuming ( $15 \mathrm{~h} /$ patients). Nevertheless, it is one of the most important series of patients with scoliosis in adults and 3D muscle analysis (and not cross-sectional area analysis). The addition of an electromyographic evaluation could have made it possible to better analyze the denervation of the muscles [32]. And of course, a dynamic study of these patients would be interesting. In addition, the assessment of fat infiltration was performed from the psoas.

Finally, although a premise of relationship between muscle degeneration and deformity is now established, we have no answer about the role of muscles as a cause or consequence of deformity. Another hypothesis on the pathophysiology of degenerative lumbar scoliosis is that the lumbar curvature is itself a compensatory mechanism after disk failure and lateral listhesis. Moreover, in clinical practice, some patients with neurological signs such as extra-pyramidal symptoms (Parkinson's disease) have progressive deformities despite a preserved physical activity. It is therefore likely that certain genetic determinants are also involved in degenerative deformity. However, few studies have been conducted in this direction and a longitudinal study on a large cohort would be necessary to know the primum movens of de novo scoliosis. Moreover, the existence of correlation between muscle parameters and quality of life raises the question of the benefit of rehabilitation with muscle reinforcement in these patients. Similarly, Miyakoshi in studies on postmenopausal women (which are often ASD patients) observed that decrease in back extensor strength was associated with poor quality of life [33, 34].

\section{Conclusion}

This study analyzed for the first time the relationship between 3D radiographic parameters and muscular characteristics in ASD. There is a great variability of muscles characteristic among patients. We observed a tendency toward a loss of volume and an increase in fat infiltration in relation to the coronal and axial parameters. Nevertheless, sagittal malalignment, particularly anterior tilt and loss of lumbar lordosis, was associated with increased fat infiltration for all muscle groups (more severely for erector spinae, hip flexor and extensor), and decreased muscle volumes were associated with worst outcomes. Thus, the detailed muscular analysis is interesting to consider in the therapeutic strategy and surgical planning to avoid some complications.

However, a longitudinal study with a larger cohort is needed to analyze the evolution of these parameters in degenerative scoliosis. In addition, the comparison with healthy subjects would help to better understand agerelated muscle degenerative phenomena and those related to deformity.

\section{Compliance with ethical standards}

Conflict of interest We have no potential conflict of interest.

\section{References}

1. Kebaish KM, Neubauer PR, Voros GD, Khoshnevisan MA, Skolasky RL (2011) Scoliosis in adults aged forty years and older: prevalence and relationship to age, race, and gender. Spine 36(9):731-736

2. Bess S, Line B, Fu K-M, McCarthy I, Lafage V, Schwab F et al (2016) The health impact of symptomatic adult spinal deformity: comparison of deformity types to United States population norms and chronic diseases. Spine 41(3):224-233

3. Pellisé F, Casademunta A, Ferrer M, Sàbat M, Bagó J, FJS et al (2015) Impact on health related quality of life of adult spinal deformity (ASD) compared with other chronic conditions. Eur Spine J Off Publ Eur Spine Soc Eur Spinal Deform Soc Eur Sect Cerv Spine Res Soc 24(1):3-11

4. Diebo BG, Varghese JJ, Lafage R, Schwab FJ, Lafage V (2015) Sagittal alignment of the spine: What do you need to know? Clin Neurol Neurosurg 139:295-301

5. Ferrero E, Liabaud B, Challier V, Lafage R, Diebo BG, Vira S et al (2016) Role of pelvic translation and lower-extremity compensation to maintain gravity line position in spinal deformity. J Neurosurg Spine 24(3):436-446

6. Diebo BG, Ferrero E, Lafage R, Challier V, Liabaud B, Liu $S$ et al (2015) Recruitment of compensatory mechanisms in sagittal spinal malalignment is age and regional deformity dependent: a full-standing axis analysis of key radiographical parameters. Spine 40(9):642-649 
7. Meakin JR, Fulford J, Seymour R, Welsman JR, Knapp KM (2013) The relationship between sagittal curvature and extensor muscle volume in the lumbar spine. J Anat 222(6):608-614

8. Kang CH, Shin MJ, Kim SM, Lee SH, Lee C-S (2007) MRI of paraspinal muscles in lumbar degenerative kyphosis patients and control patients with chronic low back pain. Clin Radiol 62(5):479-486

9. Teichtahl AJ, Urquhart DM, Wang Y, Wluka AE, Wijethilake P, O'Sullivan R et al (2015) Fat infiltration of paraspinal muscles is associated with low back pain, disability, and structural abnormalities in community-based adults. Spine J Off J North Am Spine Soc 15(7):1593-1601

10. Amabile C, Moal B, Chtara OA, Pillet H, Raya JG, Iannessi A et al (2017) Estimation of spinopelvic muscles' volumes in young asymptomatic subjects: a quantitative analysis. Surg Radiol Anat SRA 39(4):393-403

11. Zhang C, Moal B, Dubois G, Raya J, Lafage V, Skalli W (2014) Comparison of two MRI sequences for subject-specific 3D thigh muscle reconstruction. Comput Methods Biomech Biomed Eng 17(1):136-137

12. Gille O, Jolivet E, Dousset V, Degrise C, Obeid I, Vital J-M et al (2007) Erector spinae muscle changes on magnetic resonance imaging following lumbar surgery through a posterior approach. Spine 32(11):1236-1241

13. McHorney CA, Ware JE, Rogers W, Raczek AE, Lu JF (1992) The validity and relative precision of MOS short- and long-form health status scales and Dartmouth COOP charts. Results from the Medical Outcomes Study. Med Care 30(Suppl):MS253-MS265

14. Asher M, Min Lai S, Burton D, Manna B (2003) The reliability and concurrent validity of the scoliosis research society-22 patient questionnaire for idiopathic scoliosis. Spine 28(1):63-69

15. Lonjon G, Ilharreborde B, Odent T, Moreau S, Glorion C, Mazda K (2014) Reliability and validity of the French-Canadian version of the scoliosis research society 22 questionnaire in France. Spine 39(1):E26-34

16. Vogler D, Paillex R, Norberg M, de Goumoëns P, Cabri J (2008) Cross-cultural validation of the Oswestry disability index in French. Ann Readaptation Med Phys Rev Sci Soc Francaise Reeducation Fonct Readaptation Med Phys 51(5):379-385

17. Grönblad M, Hupli M, Wennerstrand P, Järvinen E, Lukinmaa A, Kouri JP et al (1993) Intercorrelation and test-retest reliability of the Pain Disability Index (PDI) and the Oswestry Disability Questionnaire (ODQ) and their correlation with pain intensity in low back pain patients. Clin J Pain 9(3):189-195

18. Faro FD, Marks MC, Pawelek J, Newton PO (2004) Evaluation of a functional position for lateral radiograph acquisition in adolescent idiopathic scoliosis. Spine 29(20):2284-2289

19. Humbert L, De Guise JA, Aubert B, Godbout B, Skalli W (2009) $3 \mathrm{D}$ reconstruction of the spine from biplanar X-rays using parametric models based on transversal and longitudinal inferences. Med Eng Phys 31(6):681-687

20. Vialle R, Levassor N, Rillardon L, Templier A, Skalli W, Guigui $P$ (2005) Radiographic analysis of the sagittal alignment and balance of the spine in asymptomatic subjects. J Bone Joint Surg Am 87(2):260-267

21. Amabile C, Pillet H, Lafage V, Barrey C, Vital J-M, Skalli W (2016) A new quasi-invariant parameter characterizing the postural alignment of young asymptomatic adults. Eur Spine J Off
Publ Eur Spine Soc Eur Spinal Deform Soc Eur Sect Cerv Spine Res Soc 25(11):3666-3674

22. Ferrero E, Lafage R, Vira S, Rohan PY, Oren J, Delsole E, Guigui P, Schwab F, Lafage V, Skalli W (2017) Three-dimensional reconstruction using stereoradiography for evaluating adult spinal deformity: a reproducibility study. Eur Spine J 26(8):2112-2120

23. Ilharreborde B, Steffen JS, Nectoux E, Vital JM, Mazda K, Skalli W et al (2011) Angle measurement reproducibility using EOS three-dimensional reconstructions in adolescent idiopathic scoliosis treated by posterior instrumentation. Spine 36(20):E1306-E1313

24. Schwab F, Farcy J-P, Bridwell K, Berven S, Glassman S, Harrast $\mathrm{J}$ et al (2006) A clinical impact classification of scoliosis in the adult. Spine 31(18):2109-2114

25. Moal B, Bronsard N, Raya JG, Vital JM, Schwab F, Skalli W et al (2015) Volume and fat infiltration of spino-pelvic musculature in adults with spinal deformity. World J Orthop 6(9):727-737

26. Dixon WT (1984) Simple proton spectroscopic imaging. Radiology 153(1):189-194

27. Ragan DK, Bankson JA (2010) Two-point Dixon technique provides robust fat suppression for multi-mouse imaging. J Magn Reson Imaging JMRI 31(2):510-514

28. Hausselle J, Assi A, El Helou A, Jolivet E, Pillet H, Dion E et al (2014) Subject-specific musculoskeletal model of the lower limb in a lying and standing position. Comput Methods Biomech Biomed Eng 17(5):480-487

29. Shafaq N, Suzuki A, Matsumura A, Terai H, Toyoda H, Yasuda $\mathrm{H}$ et al (2012) Asymmetric degeneration of paravertebral muscles in patients with degenerative lumbar scoliosis. Spine 37(16):1398-1406

30. Yagi M, Hosogane N, Watanabe K, Asazuma T, Matsumoto M, Keio Spine Research Group (2016) The paravertebral muscle and psoas for the maintenance of global spinal alignment in patient with degenerative lumbar scoliosis. Spine J Off J North Am Spine Soc 16(4):451-458

31. Hyun S-J, Kim YJ, Rhim S-C (2016) Patients with proximal junctional kyphosis after stopping at thoracolumbar junction have lower muscularity, fatty degeneration at the thoracolumbar area. Spine J Off J North Am Spine Soc 16(9):1095-1101

32. Haig AJ (2002) Paraspinal denervation and the spinal degenerative cascade. Spine J Off J North Am Spine Soc 2(5):372-380

33. Miyakoshi N, Kudo D, Hongo M, Kasukawa Y, Ishikawa Y, Shimada Y (2017) Comparison of spinal alignment, muscular strength, and quality of life between women with postmenopausal osteoporosis and healthy volunteers. Osteoporos Int J Establ Result Coop Eur Found Osteoporos Natl Osteoporos Found USA 28(11):3153-3160

34. Miyakoshi N, Hongo M, Maekawa S, Ishikawa Y, Shimada Y, Itoi E (2007) Back extensor strength and lumbar spinal mobility are predictors of quality of life in patients with postmenopausal osteoporosis. Osteoporos Int J Establ Result Coop Eur Found Osteoporos Natl Osteoporos Found USA 18(10):1397-1403 


\section{Affiliations}

Emmanuelle Ferrero $^{1,2} \cdot$ Wafa Skalli $^{2} \cdot$ Virginie Lafage $^{3} \cdot$ Cédric Maillot $^{2} \cdot$ Robert Carlier $^{4} \cdot$ Antoie Feydy $^{5}$. Adrien Felter ${ }^{4} \cdot$ Marc Khalifé $^{1} \cdot$ Pierre Guigui $^{1}$

$\triangle$ Emmanuelle Ferrero

emmanuelle.ferrero@aphp.fr

1 Department of Orthopaedic Surgery, Hopital Européen Georges Pompidou, APHP, Paris V University, 20 Rue Leblanc, 75015 Paris, France

2 Laboratoire de biomécanique Georges Charpak, Ecole Nationale supérieure Des Arts Et métiers, 75013 Paris, France
3 SpineLab, Department of Orthopaedic Surgery, Hospital for Special Surgery, New York, NY, USA

4 Department of Radiology, Hopital de Garches, APHP, Garches, France

5 Department of Radiology, Hopital Cochin, APHP, Paris V University, Paris, France 